\title{
Developing Calibration Model for Prediction of Malt Barley Genotypes Quality Traits using Fourier Transform near Infrared Spectroscopy
}

\author{
Yadesa Abeshu ${ }^{1}$ \\ Ashagrie Zewdu
}

'Food Science and Nutrition Research Program, Holeta Agricultural Research Center, Ethiopian Institute of Agricultural Research; Addis Ababa, Ethiopia.

Email:abeshuy@gmail.com Tel: +251988735020

${ }^{2}$ Center for Food science and Nutrition, College of Natural and Computational Sciences, Addis Ababa University; Addis Ababa, Ethiopia.

Email:ashagrie.zewdu@aau.edu.et Tel:+251911194508

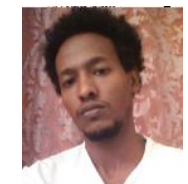

( Corresponding Author)

\begin{abstract}
Ethiopia is the second largest barley producer in Africa. But the quality traits are always influenced by the cultivar itself and growing environment. Thus, the study was targeted on developing calibration model for predicting malt barley quality traits of genotypes grown at different locations using near infra-red spectroscopy for selection purposes in barley breeding program. For this purpose, 60 barley samples were collected from Holeta, Debre-Birhan and Bekoji. Samples were chemically analyzed in duplicate for 5 barley traits. The calibration model was developed based on 120 samples spectral data and 60 chemistry data results using the calibration software of the FT-Near Infrared Spectroscopy. The barley Protein calibration model having $\left(\mathrm{R}_{\mathrm{c}}^{2}=0.97 ; \mathrm{RPD}=5.7\right.$ and $\left.\mathrm{R}_{\mathrm{c}}{ }_{\mathrm{c}}=0.94 ; \mathrm{RPD}=4.16\right)$ respectively, can be regarded as broadly applicable; Extract and Friability $\left(\mathrm{R}^{2}=0.96 ; \mathrm{RPD}=4.54\right.$ and $\left.\mathrm{R}^{2}=0.95 ; \mathrm{RPD}=4.36\right)$ respectively were accepted as useable with good prediction capability; whereas $\beta$-Glucan calibration model $\left(\mathrm{R}^{2} \mathrm{c}=0.90 ; \mathrm{RPD}=3.18\right)$ allowed only for screening purpose in some applications. Barley grain dry matter with model parameters result $\left(\mathrm{R}^{2}{ }_{\mathrm{c}}=0.86\right.$; $\left.\mathrm{RPD}=2.69\right)$ shown usable with caution only for rough screening purposes. Hence near infrared spectroscopy is fast and cost-efficient, the breeding program can increase the intensity of variety selection using calibration models reflected good predicting performances except models for dry matter and $\beta$-glucan.
\end{abstract}

Keywords: Barley, Genotypes, Malt, Trait, Near infrared spectroscopy, Calibration, Validation.

Citation | Yadesa Abeshu; Ashagrie Zewdu (2020). Developing Calibration Model for Prediction of Malt Barley Genotypes Quality Traits using Fourier Transform near Infrared Spectroscopy. Agriculture and Food Sciences Research, $7(1): 38-45$ Agriculture

History:
Received: 7 January 2020

Revised: 10 February 2020

Accepted: 17 March 2020

Published: 13 April 2020

Licensed: This work is licensed under a Creative Commons Attribution 3.0 License $(\mathrm{cc})$ Ey

Publisher: Asian Online Journal Publishing Group
Acknowledgement: Authors would like to express their gratitude to Rebeka $\mathrm{G} /$ Tsadik (PhD) GIZ contact person and coordinator in Ethiopia and BerhaneLakew $(\mathrm{PhD})$ senior barley breeder at Holeta Research Center for their kind supports to the successful attainment for the study. Their special thanks also go to Wilde Peer (PhD) KWS breeding Company senior breeding thanks also go to Wilde Peer (PhD) KWS breeding Company senior breeding
advisor and Christian Utschig (PhD) for coordinating laboratory facility at advisor and Christian Utschig (PhD) for coordinating laboratory facility at they would like to thank Addis Ababa University, Center for Food Science and Nutrition as well as Holetta Agricultural Research Center barley breeding team members and Food science and Nutrition Research Program for their support in sample collection and laboratory analysis.

Funding: The authors would like to thank the GIZ-SSAP project and KWS breeding Company of Germany which supported them in financial and technical assistance.

Competing Interests: The authors declare that they have no conflict of interests.

Transparency: The authors confirm that the manuscript is an honest, accurate, and transparent account of the study was reported; that no vital features of the study have been omitted; and that any discrepancies from the study as planned have been explained.

Ethical: This study follows all ethical practices during writing.

\section{Contents}

1. Introduction

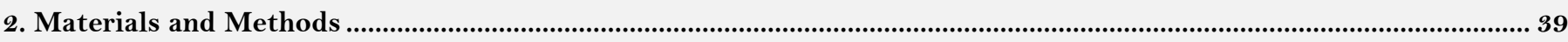

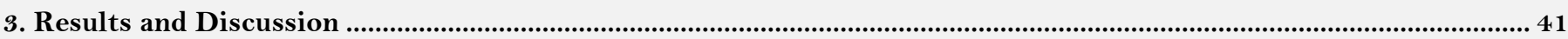

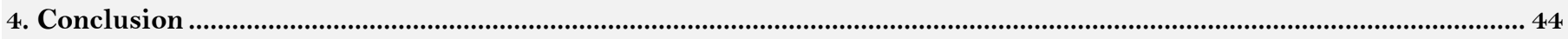

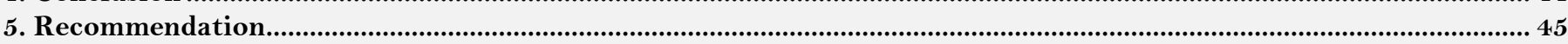

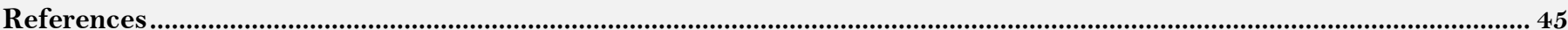




\section{Contribution of this paper to the literature}

This study was targeted on developing calibration model for predicting malt barley quality traits of genotypes grown at different locations using near infra-red spectroscopy for selection purposes in barley breeding program.

\section{Introduction}

Barley (Hordeum vulgare L.) is the fourth most important cereal crop worldwide after wheat, corn and rice [1]. But it is the fifth most important grain crop in Ethiopia and has diverse ecologies being grown from 1800 to $3400 \mathrm{~m}$ altitude in different seasons and production systems which makes Ethiopia being the second largest producer in Africa, next to Morocco. Also recognized as one of the country's most ancient food crop, which is believed to have first domesticated about 10,000 years ago from its wild relatives in the Fertile Crescent of the Near East and center of diversity in Ethiopia [2]. It is most widely used for the production of malt worldwide [3]. Barley malt also mainly used as a source of fermentable sugars for alcoholic fermentation like production of beer [4]. Barley isa complex mixture of many organic components that include protein, starch, oil, polysaccharides and sugars. The amount of each of the constituents will vary due to both the genetic background and the environmental conditions during grain development. The malting process of barley in particular, modifies the grain components during the controlled steeping, germination and drying processes. Malt is an essential ingredient in beer production where soluble components of the malt are extracted into a liquid broth called wort [5]. The ability to predict grain quality for different purposes in early generations would be of great benefit to breeders and industries, allowing for selection of suitable lines to deliver product of the highest quality. At later stages in the barley breeding programs, micro-malting can be carried which requires large barley sample sizes, destructive and requires experienced personnel. For this purpose, near infrared spectroscopy is an ideal technique as it is fast, reliable and nondestructive which does not require large sample sizes [6]. Near infrared spectroscopy is a type of vibration spectroscopy that employs photon energy in the range of $7.96 \times 10^{-20}$ to $2.65 \times 10^{-19} \mathrm{~J}$. The range is higher than necessary to promote molecules to their lowest excited vibrational states and lower than typical values necessary for electron excitation in molecules [7]. Hence, food NIR spectra comprised of broad bands arising from overlapping absorptions corresponding mainly to overtones and combinations of vibration modes involving $\mathrm{C}-\mathrm{H}$, $\mathrm{O}-\mathrm{H}, \mathrm{N}-\mathrm{H}$ and $\mathrm{SH}$ chemical bonds [8]. Thus, sophisticated mathematical techniques, termed chemometrics, are heavily employed to allow calibration for reliable extraction of relevant information encoded in the NIR spectral data [9]. The aim of this study is to determine constituents of particular interest for the brewing of barley grain criterion important traits by using NIRS. This was performed using Near Infra-Red Reflectance (NIR) technology which is effective in simultaneously predicting of multiple constituents in agricultural products.

\section{Materials and Methods}

\subsection{Materials}

The samples used in this study were from barley breeding program trials of Ethiopian Institute of Agricultural Research Centers having the mandate of barley growing and breeding potential around central highland areas of Ethiopia. Thus, barley samples were collected representing a range of breeding generations fully-fledged at different environments throughout barley growing highland areas, specifically from Holeta, Debre Birhan and Bekoji locations. About 60 samples from 2018 year of barley growing season were collected from the pre-specified growing areas for the study. Particularly, from the plot of the breeding program-controlled trials depending on genotypes, location, type (food or malt barley) and quality variability.

\subsection{Sample Preparation}

Barley samples which were collected from different locations and different genotypes of breeding trials were selected purposively from different plots depending on agronomical data and source of genotypes from where they originated as well as the history of their quality data. For barley reference and spectral data analysis $150 \mathrm{~g}$ per sample was taken after manually cleaned and graded. Then the samples were packed into plastic bag. Prior to reference samples chemical analysis, malt(after malted)were ground using a Laboratory Sample Mills 100 (Perten Instruments, Hagersten, Sweden) to pass through $0.5 \mathrm{~mm}$ sieve for calibration reference data. But for malt friability determination the malt sample was not grounded, because the friabilimeter machine itself grounds the sample for the ratio of friability measurement.Before malt quality traits analysis, the malt barley samples were malted according to Phoenix Automated Micro malting system (Phoenix Bios stems, Adelaide, Australia) designed to process $300 \mathrm{~g}$ of 24 barley samples per batch [10]. After kilning the rootlets were removed from the malted samples by using mechanical malt cleaner that had been reconfigured to simultaneously process eight $250 \mathrm{~g}$ samples (Fraser Fabrications Pty Ltd, Malaga Western Australia).

\subsection{Wet Chemistry Analysis}

Malt quality traits of malt barley were chemically analyzed for reference data at Holeta Food science and Nutrition Laboratory, EIAR (Ethiopian Institute of Agricultural Research) in collaboration with VLB Institute in Berlin (Germany) for the traits mentioned below. But simple quality traits were analyzed at Holetta, EIAR cereal quality laboratory. Blank and known concentration sample were analyzed with the samples to control the analysis biases. The samples also duplicated to reduce the reproduced errors in each sample chemical analysis.

\subsubsection{MaltExtract Content}

Malt extract content was determined according to a small-scale version of the European Brewery Convention [11] Methods Manual, Section 4.9.1. Fine grind malt was extracted using a hot water mashing bath (SIEMENS Mashing Machine, Germany).For extraction, $50 \mathrm{~g}$ of finely ground malt was mixed with $200 \mathrm{~mL}$ of distilled water and mash at $45^{\circ} \mathrm{C}$ with continuous stirring. After 30 minutes of mashing, the temperature was increased by $1^{\circ} \mathrm{C} / \mathrm{min}$ until $70^{\circ} \mathrm{C}$. As temperature reaches $70^{\circ} \mathrm{C}$, there was added of $100 \mathrm{~mL}$ distilled water. After 1 hour, the mash was cooled to $30^{\circ} \mathrm{C}$ and adjusted to a volume of $515 \mathrm{~mL}$ or a weight of $450 \mathrm{~g}$. The extract was filtered using 
whatman $12 \mathrm{~cm}$ filter paper into $500 \mathrm{ml}$ cylinder and specific gravity was measured at $20^{\circ} \mathrm{C}$ using a DMA5000 density meter (Anton Paar GmbH, Graz, Austria). Therefore the following formula was used to put the end result. $\mathrm{E}=\mathrm{P}(800+\mathrm{M}) /(100-\mathrm{P})$; where, $\mathrm{E}=$ Extract content, $\mathrm{P}=$ Wort Density ( $\left.{ }^{\circ} \mathrm{Plato}\right), \mathrm{M}=$ Malt Moisture content.

\subsubsection{Malt Total Protein}

The malt protein content was determined using kjeldhal method (Digester SBS 2000, Distillation Unit 500oDL, FoodALYTGimbH, Germany) according to AOAC [12]. For analysis one gram ground sample of malt barley was measured and transferred into completely dry kjeldhal flask. Ten gram of kjeldhal tablet was added to the sample inside the flask. Twenty milliliter of $98 \%$ concentrated sulphuric acid was mixed with the sample. The sample digestion was started by connecting the kjeldhal flasks with the digestion rock. The digestion was completed when the brown color of the sample completely disappeared. After the digested sample was cooled, 100 $\mathrm{ml}$ of distilled water and $80 \mathrm{ml}$ of sodium hydroxide (32\%) were added and distilled into $25 \mathrm{ml}$ of excess boric acid containing $0.5 \mathrm{ml}$ of screened indicator. The distillate was titrated with $0.1 \mathrm{~N}$ hydrochloric acid to the methyl red end point. The protein was calculated by using this formula: $\left.\mathrm{CP} \%=\left[(\mathrm{T}-\mathrm{B})^{*} 14^{*} 6.25\right)\right] /[\mathrm{W}(100-\mathrm{MC})]$; where $\mathrm{CP}=$ Crude Protein, $\mathrm{T}=$ Volume of $\mathrm{HCl}$ used in Titration, $\mathrm{B}=$ Blank used as control and $\mathrm{W}=$ Weight of sample taken for analysis.

\subsubsection{Malt Friability}

Malt grain samples were analyzed using a friability measuring machine (PfeufferFriabilimeter GmbH, Germany) which is used as pressure roller to grind the sample against a rotating screen. Low, medium and high friability malts were tested according to EBC method 4.15 [11]. $50 \mathrm{~g}$ malt sample was run in the friabilimeter for 8 min and the non-friable fraction was weighed to get the final result.

\subsubsection{Malt $\beta-G l u c a n$}

The malt $\beta$-glucan content was determined using the Megazyme kit method (Megazyme, Bray, Ireland)according to European Brewery Convention [11] Method 4.16.1.For the analysis $100 \mathrm{mg}$ sample was suspended and hydrated in a buffer solution of $\mathrm{pH} 6.5$ and incubated with purified lichenase enzyme and filtered. An aliquot of the filtrate was then hydrolyzed to complete with purified $\beta$-glucosidase. The D-glucose produced was assayed using a glucoseoxidase/peroxidase reagent. The final prepared aliquot was measured by spectrophotometer at absorbance $510 \mathrm{~nm}$ against reagent blank within one hour. Finally the beta-glucan was calculated using the formula;B-glucan $(\% \mathrm{~W} / \mathrm{W})=\Delta \mathrm{A} *(\mathrm{~F} / \mathrm{W}) * 27$; Where, $\Delta \mathrm{A}=$ Absorbance after $\beta$-glucosidase treatment (reaction) minus reaction blank absorbance, $\mathrm{F}=$ Factor for the conversion of absorbance values to $\mu \mathrm{g}$ of glucose, $\mathrm{W}=$ The calculated dry weigth of the sample analyzed in $\mathrm{mg}$.

\subsubsection{Dry Matter Content}

Barley grain dry matter content was determined according to AOAC [12] international standard method from grain flour prepared using the above sample preparation method. $5 \mathrm{~g}$ of barley flour was taken using a sensitive analytical balance and oven dried at $105^{\circ} \mathrm{C}$ temperature for 3 hours. After the dried sample was cooled in a desiccator, the final measurement was taken using the same analytical balance to get the result using the following known formula for moisture content. $\mathrm{MC} \%=\left(\mathrm{W}_{\mathrm{i}}-\mathrm{W}_{\mathrm{f}}\right) / \mathrm{W}_{\mathrm{i}} * 100$; where $\mathrm{W}_{\mathrm{i}}$ is initial weight, $\mathrm{W}_{\mathrm{f}}$ is Final Weight; $\mathrm{DM}=(100-\mathrm{MC}) \%$.

\subsubsection{Samples Spectral Data Acquisition}

Before scanning the samples, the spectroscopic performance of the device was checked using gold standard (1.038) and light trap standard (0.00065) provided by Bruker company of Germany. Then 60 barley samples were scanned twice for spectral data using near infrared spectrometer (Tango2017, Bruker Optics GmbH, Germany) which uses scan and rotating mode within 16 seconds, sample presentation with rotating accessory having $600 \mathrm{~mL}$ sample cuvette. It used32 amounts of scans between $867-2535 \mathrm{~nm}$ wave length ranges with $16 \mathrm{~cm}^{-1}$ wave number band resolution. The NIR sensor used in this experiment is capable of recording spectra by diffusive reflectance measurements at the mentioned spectral wave length range. Spectra data figure-1 shown below was acquired from untreated barley grains before malting using a Bruker Tango software. It is the raw spectral data which needs to be treated statistically to correct spectral biases. The device recorded spectra in diffusive reflectance by using an integrating sphere. Measurements were done in duplicate for each sample, leading to a total number of 120 spectral data.

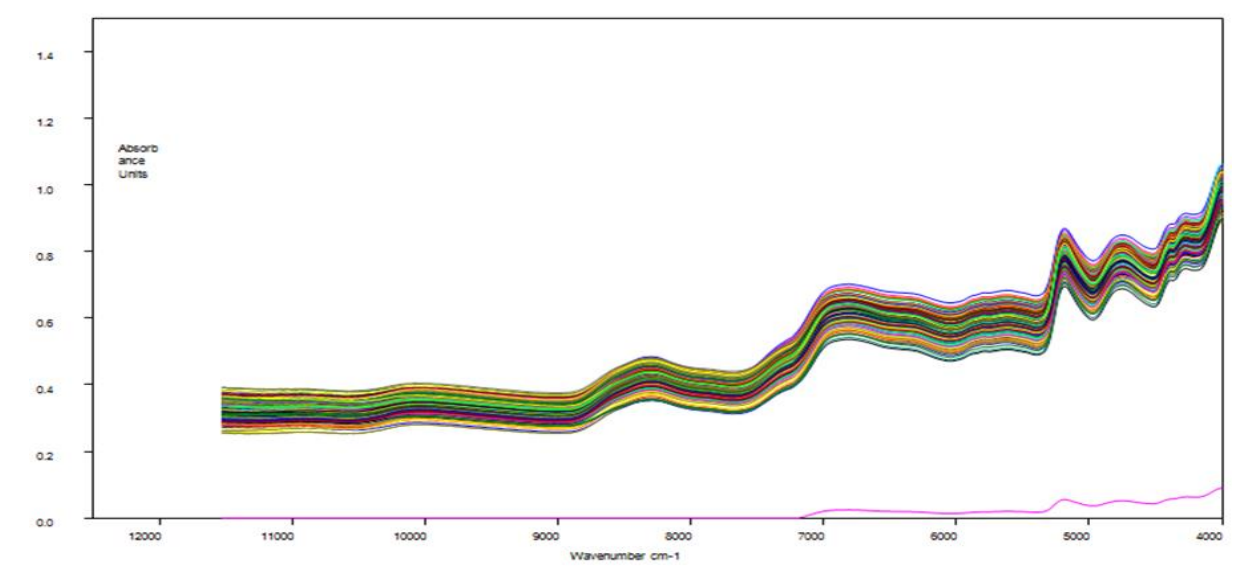

Figure-1. Barley samples component matrix raw spectral data collected by NIR. 


\subsection{Spectral Data Pre-Processing}

There were spectral biases and overlaps of wave length bands due to matrix effect, different particle size and spectroscopic condition. For this matter spectral data obtained according to figure-1 above must be pre-processed using the mathematical manipulation of the NIR machine as follows. The spectral data shown at figure- 2 below was pre-processed using chemometrics system of FT-IR's OPUS software version 7.5.1. Therefore, first Derivative plus Standard Normal Variate $\left(1^{\text {st }} \mathrm{D} / \mathrm{ve}+\mathrm{SNV}\right)$ transformations, with 17 smoothing points were found to be the best method for the above spectral data treatment/pre-processing. The above Figure 1 raw spectral data was changed to the spectral data shown below in Figure 2. The shape and the resolution of the spectral data was completely changed as reflected below after preprocessed. So, the main objective of spectral data pre-processing was to remove biases, unwanted outliers and increase the resolution of overlapped wave length bands that could result errors in development of calibration model.

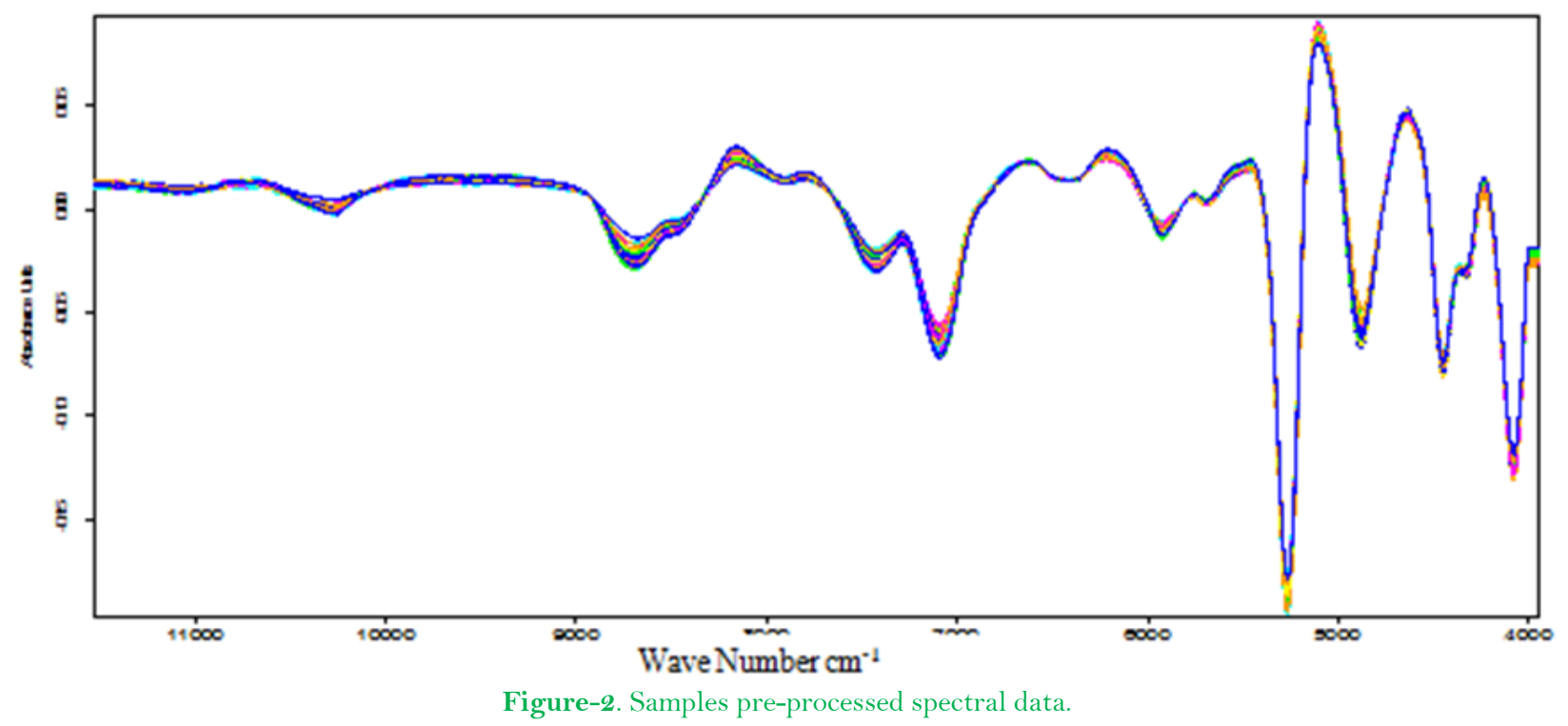

\subsection{Developing Calibration and Validation}

The laboratory reference data was correlated with spectral data using the software OPUS version7.5.1 of Tango (Bruker, Optics GmbH, Germany). In total, 120 spectral data were used for calibration and validation. From 120 spectral data, with approximately two thirds of the samples were used in the calibration set and one third in the validation set. Validation method used to check the performance of the calibration model was test set validation method. The calibration set was checked to cover the whole variation in terms of spectral data, traits and locations. The following numbers of factors were used for the traits of interest: protein content 8 , extract content 8 , friability 9, B-Glucan 10 and dry mater 10.The calibration model result was evaluated by using OPUS software statistical systems (chemometrics) [13].

\subsection{Calibration Model Statistical Evaluation}

Statistical tools were used to evaluate the efficiency of NIR calibrations and various terms are important in understanding the performance of a calibration model as described by Williams [14]. This includes statistics of calibration as well as statistics of validation. For developing calibration model a Partial Least Square (PLS) regression was used which was performed using OPUS software.

The Coefficient of Determination $\left(\mathrm{R}^{2)}\right.$, Root Mean Square Error Estimation (RMSEE), Root Mean Square Error of Prediction (RMSEP), Ratio of performance to Deviation (RPD), Standard Deviation (SD) and Standard Error of Prediction) good parameters to evaluate the model performance depending on the reference data and spectra. The calibration was automatically tested by test set validation method. The final calibration was determined from an optimization routine of OPUS after the removal of the outliers. During the optimization step, various frequency regions and also spectral pre-treatments was systemically tested to determine the optimal calibration that was directly stored in the device memory for future quantitative analysis as used by Krapf, et al. [13].

\section{Results and Discussion}

Calibration model development highly depends on selecting a set of good calibration samples data obtained by wet chemistry analysis method. The set of calibration samples used in this study also contained the range of chemical and physical variations for which calibration model was applied. Accordingly, the calibration experiment was established using a mathematical relationship between the NIR spectrum and physical/chemical properties determined by reference methods. Similarly, comparing the chemical reference data variability and model accuracy is vital point.

\subsection{Calibration Model}

NIRS calibration models were developed for five barley traits determining quality for malt and food use. The model performance was assessed by the following parameters: coefficient of determination of the calibration $\left(\mathrm{R}^{2} \mathrm{c}\right)$ and validation set $\left(\mathrm{R}^{2} \mathrm{v}\right)$, standard errors of prediction (SEP) as well as root mean square error of prediction (RMSEP). The RPDv value indicates the suitability of the calibration for the prediction. With a higher RPDv value the calibration will more likely be able to predict the right sample values. According to the generally used classification in agriculture based on RPDv-values and $\mathrm{R}^{2} \mathrm{c}^{-v}$ alues, the calibration for protein can be regarded as successful calibration [15]. 
The calibration and validation statistical description was very important to see the feasibility of each traits data to build calibration model. Table 1 implies the general features of descriptive statistics of traits to detect the right data variability for developing strong calibration model. Good data variability was observed in all traits except for DM as shown in Table 1 below. Therefore, expected calibration model is good for all traits if could not be strong model for DM only i.e. not implying the good fitness between reference data and spectral data, it is all about to capture the range of traits value obtained from different barley samples.

Table-1. Descriptive statistics for calibration and validation

\begin{tabular}{|c|c|c|c|c|c|c|c|c|c|}
\hline & & \multicolumn{4}{|c|}{ Calibration Data } & \multicolumn{4}{|c|}{ Validation Data } \\
\hline Traits & Units & Mean & Range & SD & $\mathbf{N}_{\mathrm{c}}$ & Mean & Range & SD & $\mathbf{N}_{\mathrm{v}}$ \\
\hline Extract & $\%$ & 78.1 & $73-83.5$ & 2.93 & 120 & 78.1 & $69.9-84$ & 3.12 & 60 \\
\hline Protein & $\%$ & 10.4 & $7-14.1$ & 1.88 & 120 & 10.5 & $6.8-13.3$ & 2.08 & 60 \\
\hline Friability & $\%$ & 61.0 & $29-97$ & 18.96 & 120 & 59 & $20-98$ & 22.13 & 60 \\
\hline$\beta$-glucan & $\mathrm{Mg} / \mathrm{L}$ & 685.0 & $158-1000$ & 279.5 & 120 & 699 & $50-1000$ & 358.6 & 60 \\
\hline DM & $\%$ & 91.34 & $90.6-92.3$ & 0.4 & 120 & 91.28 & $90.8-91.9$ & 0.26 & 60 \\
\hline
\end{tabular}

The following barley traits analyzed chemically using wet chemistry methods were assigned for calibration model to fit the true value with predicted spectral value using PLS statistical regression. Spectral data was pretreated using appropriate statistical tool to remove outliers and to check the status of the chemistry and spectral data for developing calibration model as planned.

\subsection{Extract Content Model}

Extract content prediction delivered good calibrations as in Table 2 for whole grain samples $\left(\mathrm{R}^{2} \mathrm{c}=0.956\right.$; $\mathrm{RPD}_{\mathrm{C}}=4.54$ with variable samples). The model major parameters $\mathrm{R}^{2}$ and $\mathrm{RPD}$ reflect acceptable for most applications and screening purposes. Results from this study was comparable and much better than that of previous researchers who developed promising calibrations for predicting the extract of whole grain $\left(\mathrm{R}^{2} \mathrm{c}=0.78-0.85\right)[16]$ and ground barley $\left(\mathrm{R}^{2} \mathrm{c}=0.77-0.96\right)[17]$. Because this property is highly influenced by the malting process since enzyme activity during malting influences the malt extract which limits the accuracy of any NIR prediction based on not malted barley. This is why different calibration model performance is reported by different scientists, even if the accuracy of reference sample analysis data is very important. Additionally, the following Figure 3 expressed the calibration curve obtained from chemistry/reference data and NIR predicted spectrum data of extract content.

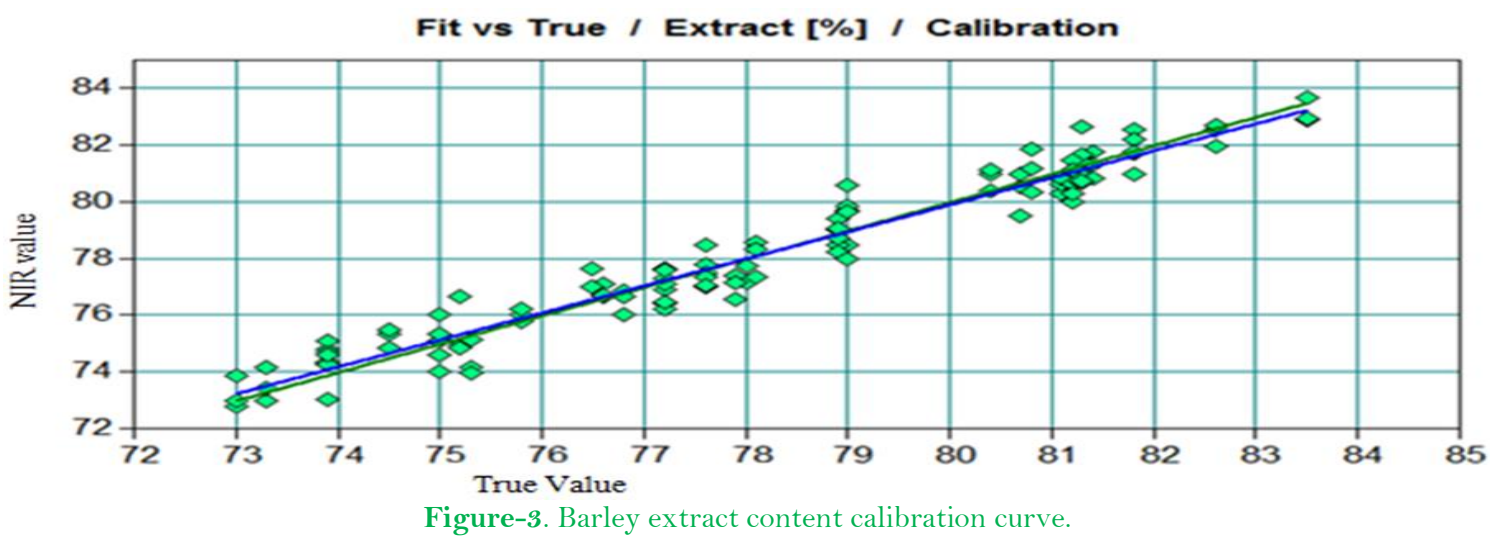

\subsection{Protein Model}

Similarly calibration model results were obtained for whole barley grain samples protein content with $\left(\mathrm{R}^{2}{ }_{\mathrm{c}}=\right.$ 0.97 ; RPD $=5.7$ of variable samples)as in Table 2 . The model is more acceptable than the models for other traits which could be usable in most applications, quality assurances and quality control. This prediction of nitrogen content from whole grain barley is well established in the literature and the results from this study compared well with those of previous reports for whole grain barley with $\mathrm{R}_{\mathrm{c}}=0.94$ [18] and $\mathrm{R}_{\mathrm{c}}=0.95$ [19]. Because NIR prediction is more effective in predicting biochemical properties than physical properties according to my observation from different literatures report. In addition to model parameter information, the following Figure 4 expressed the calibration curve obtained from reference data and NIR predicted spectrum data of protein content.

Fit vs True / Protein [\%] / Calibration

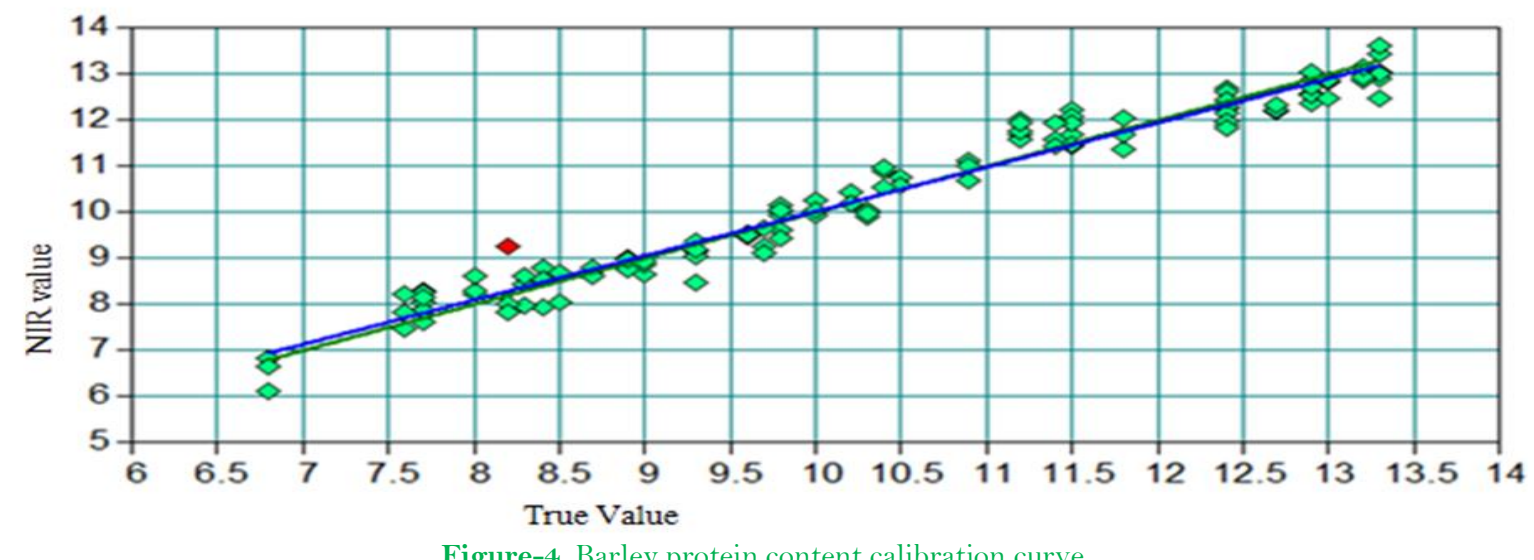




\subsubsection{Friability Model}

Friability prediction performance model shown in Table $\mathcal{Q}$ of this study was $\left(\mathrm{R}_{\mathrm{c}}{ }_{\mathrm{c}}=0.95 ; \mathrm{RPD}=4.36\right)$, which was excellent like the protein model which could be used in most applications including in quality assurances, but in our case it was trustful model to identify excellent barley friability for malt factories at breeding final stage. Almost similar performed model was also reported in the literature with parameters value $\left(\mathrm{R}^{2}{ }_{\mathrm{c}}=0.91 ; \mathrm{RPD}=3.33\right)$. Therefore, the friability calibration model was not as such challenging like in dry matter and beta-glucan as observed from similar model reported by different authors [15]. Additionally, Figure 5 expressed the calibration curve obtained from chemistry/reference data and NIR predicted spectrum data of friability content. This curve was built after exaggerated outliers were removed from the spectrum data manually as well as by the OPUS system.

Fit vs True / Friability [\%] / Calibration

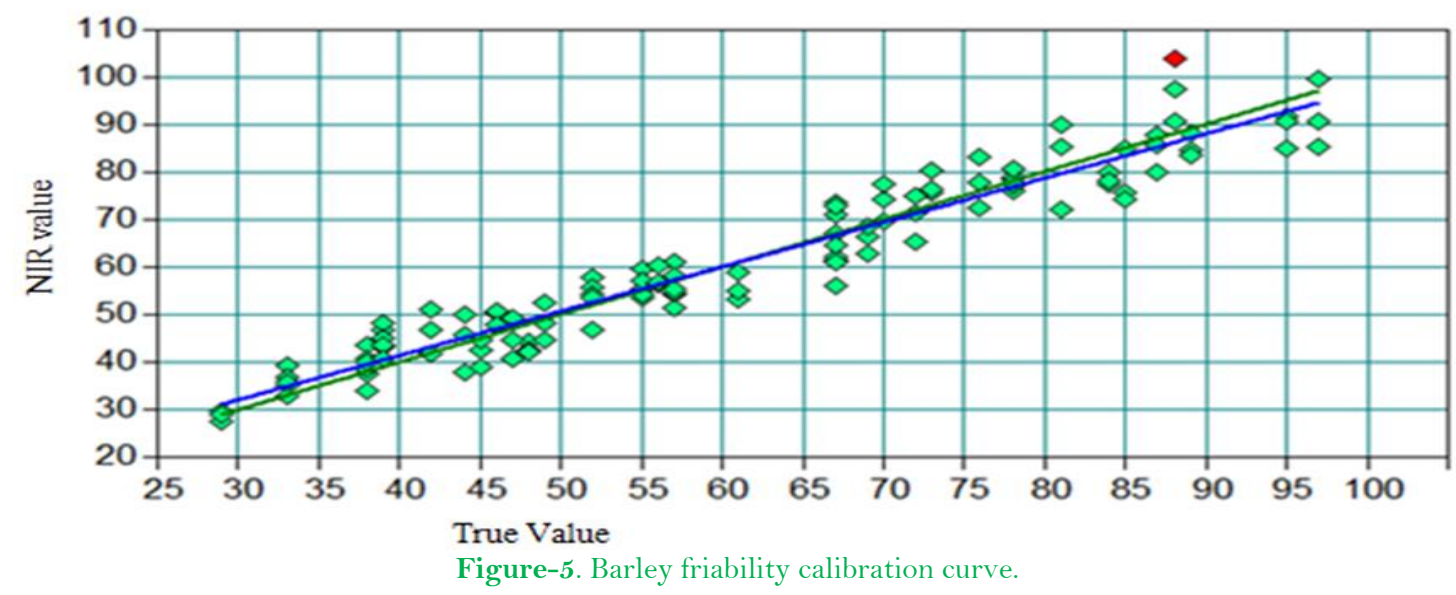

\subsection{2. $\beta$-Glucan Model}

Beta-glucan prediction model was successful in this study for whole grain barley samples having $\left(\mathrm{R}^{2}=0.90\right.$; $\mathrm{RPD}=3.18$ ) as in result Table 2. According to Williams [14] this type of model performance is usable with caution specially for screening purposes such like in early stage breeding lines. But a similar study have been reported in the literature with much lower $\left(\mathrm{R}_{\mathrm{c}}=0.25\right)$ as compared to this study by Black and Panozzo [16]. On the other hand $[20]$ reported $\left(\mathrm{R}^{2}{ }_{\mathrm{c}}=0.61\right)$ and he referred that the poor distribution of reference values in the sample range may be the reason for the poor results in Beta-glucan model of barley grain that were obtained in his study. But in this study the good modifying malting process, excellent sample variability selection and moderate accurate chemistry analysis made the model better as compared to the reported literature. Additionally, the Figure 6 expressed the calibration curve obtained from chemistry/reference data and NIR predicted spectrum data of $\beta$-glucan content.

Fit vs True / Beta-glucan [mg/L] / Calibration

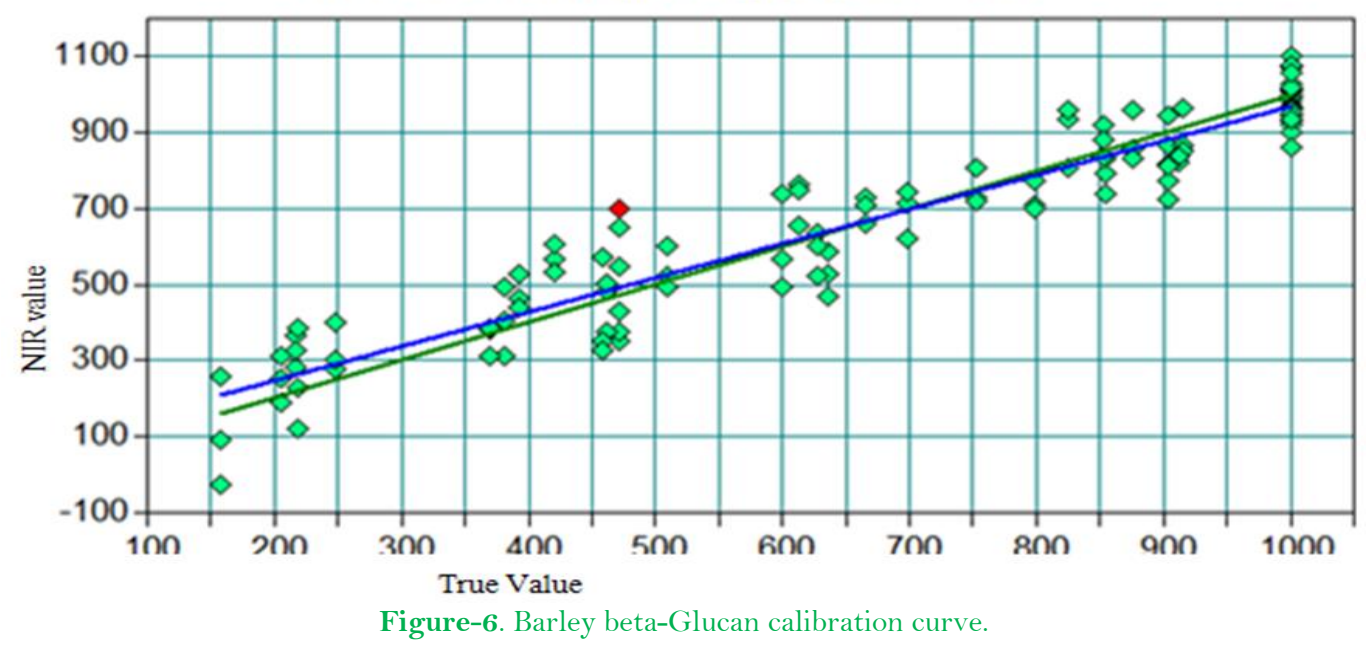

\subsubsection{Dry Matter Model}

Moisture predictions model from the same whole barley grain samples were good as in Table 2, but was only acceptable for some screening purposes, because $\left(\mathrm{R}^{{ }^{2}}=0.86 ; \mathrm{RPD}_{\mathrm{c}}=2.69\right)$ was less as compared to the recommended range by Williams [14]. Results of moisture content from this study are not comparable well to literature reports, this is due to the smaller sample moisture content ranges (90.6-92.3\% DM) utilized compared to those used by previous researchers. Similar problem was also observed in literatures with the small sample range (78.4-83.4\% DM) with in reference values obtained as studied by Roux [20]. The range of samples needs to be expanded in order to obtain acceptable calibrations model. Additionally, the Figure 7 expressed the calibration curve obtained from chemistry/reference data and NIR predicted spectrum data of dry matter content. 
Fit vs True / DMC [\%] / Calibration

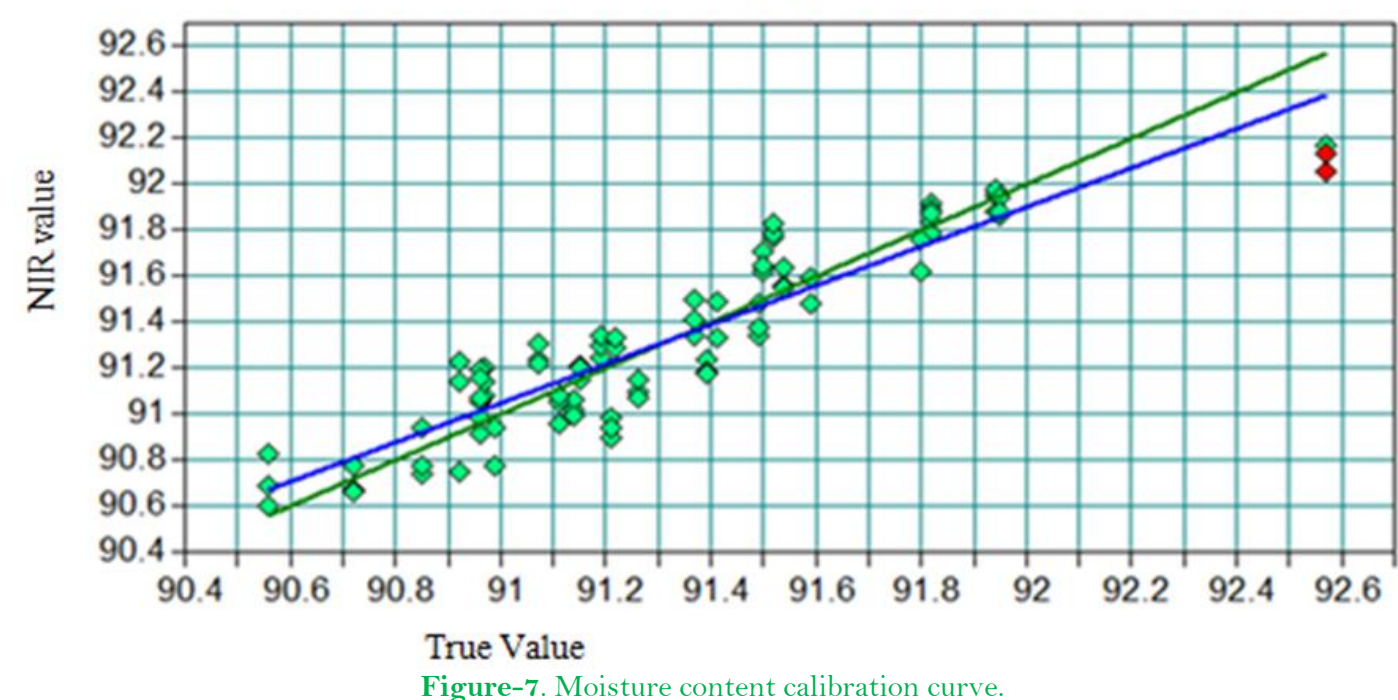

Generally, calibration model for the three traits extract content, protein content and friability were promising model for value predicting in some applications while beta-glucan and DM was delivered not trusted model as observed in the result Table 1 below. But calibration model alone does not enough to judge traits model to be applicable for targeted purpose. It is very important to see the validation parameters result side by side with the calibration parameters result as clearly shown in Table 2 for all selected traits in this study.

Table-2. Calibration and validation statistical parameters results.

\begin{tabular}{c|c|c|c|c|c|c|c|c|c|c}
\hline \multicolumn{4}{c}{ Calibration Statistical Parameters } & \multicolumn{4}{c}{ Validation Statistical Parameters } \\
\hline Traits & $\mathbf{R}^{2}$ & SEC & RMSEE & RPD & slope & $\mathbf{R}^{\mathbf{v}}$ & SEP & RMSEP & RPD & Bias \\
\hline Extract & 95.62 & 0.65 & 0.67 & 4.54 & 0.95 & 0.81 & 1.37 & 1.34 & 2.28 & 0.062 \\
\hline Protein & 96.93 & 0.33 & 0.34 & 5.7 & 0.97 & 0.93 & 0.55 & 0.54 & 3.78 & -0.03 \\
\hline Friability & 94.75 & 4.35 & 4.5 & 4.36 & 0.95 & 0.59 & 14.10 & 13.8 & 1.57 & 0.32 \\
\hline$\beta$-glucan & 90.11 & 87.90 & 91 & 3.18 & 0.90 & 0.49 & 254.33 & 249 & 1.41 & -22.6 \\
\hline DM & 86.23 & 0.15 & 0.153 & 2.69 & 0.86 & 0.51 & 0.18 & 0.29 & 1.43 & -0.001 \\
\hline
\end{tabular}

RMSEE $=$ Root Mean Square Error of Estimation, RPD=Ratio of Performance to Deviation.

\subsection{Traits Validation Model}

Model evaluation was performed by test set validation; because test set validation is a more independent validation method than cross-sectional validation as Williams [14]. In this method, the set of calibration samples is divided into a calibration set and validation set. According to this study from 60 samples,20 samples spectral data and chemistry data was set for validation. Using this process, the models were validated and checked for their prediction capacities. The principle was predicting quantitative value using the model from the validation set spectral data and comparing the predicted value against the chemistry data set for validation.

Validation parameters for each barley traits were acceptable as in Table 2 for Extract content, protein content and friability having $\left(\mathrm{R}^{2}{ }_{\mathrm{V}}=0.81 \& \mathrm{RPD}=2.28\right),\left(\mathrm{R}^{2} \mathrm{v}=0.93 \quad \& \mathrm{RPD}_{\mathrm{V}}=3.78\right)$ and $\left(\mathrm{R}^{2} \mathrm{~V}=0.59 \& \mathrm{RPD}_{\mathrm{V}}=1.57\right)$ values respectively. These models could be applied for quality control and screening purposes in breeding programs or any other applications. But as previously observed in calibration model above validation result for beta-glucan $\left(\mathrm{R}^{2} \mathrm{v}=0.49\right.$ with $\left.\mathrm{RPD} \mathrm{V}_{\mathrm{V}}=1.41\right)$ and $\mathrm{DM}\left(\mathrm{R}^{2}{ }_{\mathrm{V}}=0.51\right.$ with $\left.\mathrm{RPD} \mathrm{D}_{\mathrm{V}}=1.43\right)$ was not reflected good model even though could be used in some rough screening purposes. This kind of model was not widely usable for prediction as Black and Panozzo [16] reported unless for simple rough screening purpose. Other parameters like SEP $\backslash$ RMSEP and Bias with lower value reflected that the model was well performed. These validation parameters showed very convincing value that the user could believe the model to use for prediction of protein, extract and friability in general. Similarly, a study by [18] delivered excellent prediction models for these traits that could be used in most applications. This should be due to the nature of the sample and less modifying malting process.

\section{Conclusion}

Barley is the fourth most important cereal crop worldwide. Also, it is a crop of ancient origin in Ethiopia and is considered as a center of diversity for barley, because of the presence of great diversity in ecology. Most of the Ethiopian barley is consumed as food at home. At the same time using barley for malt production establishes new value-added chains from which Ethiopian small holders can benefit significantly. The main objective of this study was enabling the breeding programs to select the appropriate genotypes easily by developing calibration model using near infrared spectroscopy. Depending on the objective Samples wet chemistry for barley (Extract, protein, friability, beta-glucan and moisture content) were analyzed using the international official methods described in materials and method part. Likewise, calibration models were developed for all above mentioned traits using NIR OPUS software statistical parameters. These wet chemistry and calibration model results demonstrated a realistic approach to predict quality traits of Ethiopian barley protein content, extract content, friability, B-glucan and dry matter by applying NIRS.

Therefore, this prediction model will enable the selection of appropriate food and malt barley genotypes for future end goals. Since NIRS is fast and cost-efficient the barley breeding programs can increase the intensity of selecting superior candidate lines for variety verification. Also with regard to broadening calibration performance Ethiopian barley landraces were included in the samples to capture the whole Ethiopian barley variability. 


\section{Recommendation}

Malt quality traits that could have direct or indirect correlation with the identified traits should be included for model development to reduce matrix effect. For some of the traits like dry matter and beta-glucan further study is very important to distinguish between sample variability range and wet chemistry analysis inaccuracy which could contribute to results less trusted model observed in most studies. Also, to develop most excellent prediction method for barley, excellent sample variability, accurate wet chemistry data and having good instrument condition is very important.

\section{References}

[1] S. Marwat, M. Hashimi, and K. Khan, "Barley (Hordeum vulgare L.) A prophetic food mentioned in Ahadith and its ethnobotanical importance," American-Eurasian Journal of Agricultural ङ゚ Environmental Sciences, vol. 12, pp. 835-41, 2012.

FAO, "Food balance sheets. Faostat. Rome. Retrieved from: http://faostat3.fao.org/download/fb/fbs/e," 2014.

[3] S. E. Ullrich, Genetics and breeding of barley quality attributes. In: Barley Science: Recentadvances from molecular biology to agronomy of yield and quality (edited by G.A. Slafer, J.L. Molina-Cano, R. Savin, J.L. Araus\& I. Romagosa). Binghamton, New York: The Haworth Press, 2002 .

[4] S. Kreisz, Malting. In: Handbook of brewing: Processes, Technology, Markets (edited by H.M. Eßlinger). Weinheim: Wiley-VCH VerlagGmBH\& Co. KGaA, 2009

[5] D. E. Briggs, Hough. JS, Stevens, R. E Young, TW ‘. Malting and brewing science'. London: Chapman and Hall, 1981.

[6] T. Woodcock, G. Downey, and C. P. O'Donnell, "Better quality food and beverages: The role of near infrared spectroscopy," Journal of Near Infrared Spectroscopy, vol. 16, pp. 1-29, 2008. Available at: https://doi.org/10.1255/jnirs.758.

[7] C. Pasquini, "Near infrared spectroscopy: Fundamentals, practical aspects and analytical applications," Journal of the Brazilian Chemical Society, vol. 14, pp. 198-219, 2003. Available at: https://doi.org/10.1590/s0103-50532003000200006.

[8] H. Huang, H. Yu, H. Xu, and Y. Ying, "Near infrared spectroscopy for on/in-line monitoring of quality in foods and beverages: A review," Journal of Food Engineering, vol. 87, pp. 303-313, 2008. Available at: https://doi.org/10.1016/j.jfoodeng.2007.12.022.

[9] W. Wang and J. Paliwal, "Near-infrared spectroscopy and imaging in food quality and safety," Sensing and Instrumentation for Food Quality and Safety, vol. 1, pp. 193-207, 2007. Available at: https://doi.org/10.1007/s1 1694-007-9022-0.

[10] M. Nilsen and J. Panozzo, In: Leaping ahead with near infrared spectroscopy. Ed by Batten, G.D., Flinn, P.C., Welsh, L.A. and Blakeney, A.B. Australia: NIR Spectroscopy Group, 1995.

[11] European Brewery Convention, Analytica EBC, 5th ed. Nurnberg, Germany: Verlag Hans Carl, 1998.

[12] AOAC, Official methods of analysis, 17th ed. USA: Association of Official Analytical, 2000.

[13] L. C. Krapf, A. Gronauer, U. Schmidhalter, and H. Heuwinkel, "Near infrared spectroscopy calibrations for the estimation of process parameters of anaerobic digestion of energy crops and livestock residues," Journal of Near Infrared Spectroscopy, vol. 19, pp. 479-493, 2011. Available at: https://doi.org/10.1255/jnirs.960.

[14] P. C. Williams, Implementation of near-infrared technology. In: Near-Infrared Technology inthe Agricultural and Food Industries (edited by P.C. Williams \& K.H. Norris). USA: St. Paul, Minnesota, 2001.

[15] G. Fox, M. G. Borgognone, P. Flinn, and D. Poulsen, "Genetic and environmental analysis of NIR feed quality predictions on genotypes of barley (Hordeum vulgare L.)," Field Crops Research, vol. 120, pp. 380-386, 2011. Available at: https://doi.org/10.1016/j.fcr.2010.11.007.

[16] C. Black and J. F. Panozzo, "Utilising Near infrared spectroscopy for predicting malting quality in whole grain barley and whole grain malt," in Proceedings of the 10th Australian BarleyTechnical Symposium, Canberra, ACT, Australia, 2001.

[17] S. Tragoonrung, P. Hayes, and S. Broich, "Near-infrared reflectance estimates of grain protein and malt extract in hill and row plot evaluations of spring malting barley," Canadian Journal of Plant Science, vol. 70, pp. 71-78, 1990. Available at: https://doi.org/10.4141/ cjps90-008.

[18] M. Edney, J. Morgan, P. Williams, and L. Campbell, "Analysis of feed barley by near infrared reflectance technology," Journal of Near Infrared Spectroscopy, vol. 2, pp. 33-41, 1994. Available at: https://doi.org/10.1255/jnirs.29.

[19] M. Sohn, D. S. Himmelsbach, F. E. Barton, C. A. Griffey, W. Brooks, and K. B. Hicks, "Near-infrared analysis of whole kernel barley: Comparison of three spectrometers," Applied Spectroscopy, vol. 62, pp. 427-432, 2008. Available at: https://doi.org/10.1366/000370208784046768.

[20] E. Roux, "Near infrared (NIR) spectroscopy for selection of malting barley in South African breeding programmes," Doctoral Dissertation, Stellenbosch: University of Stellenbosch, 2011. 